\title{
A 6-month, subject-masked, randomized controlled study to assess efficacy of dexamethasone as an adjunct to bevacizumab compared with bevacizumab alone in the treatment of patients with macular edema due to central or branch retinal vein occlusion
}

\author{
This article was published in the following Dove Press journal: \\ Clinical Ophthalmology \\ 3 June 2014 \\ Number of times this article has been viewed
}

\author{
Raj K Maturi ${ }^{1,2}$ \\ Vincent Chen ${ }^{3}$ \\ Dan Raghinaru ${ }^{3}$ \\ Laurie Bleau' \\ Michael W Stewart ${ }^{4}$ \\ 'Midwest Eye Institute, Indianapolis, \\ IN, USA; ${ }^{2}$ Department of \\ Ophthalmology, Indiana University \\ School of Medicine, Indianapolis, \\ IN, USA; ${ }^{3}$ Jaeb Center for Health \\ Research, Tampa, FL, USA; \\ ${ }^{4}$ Department of Ophthalmology, Mayo \\ Clinic, Jacksonville, FL, USA
}

Aims: To determine if intravitreal bevacizumab combined with the dexamethasone intravitreal implant $0.7 \mathrm{mg}$ improves visual acuity and macular thickness more than bevacizumab monotherapy in eyes with macular edema due to branch and central retinal vein occlusions.

Methods: Thirty eyes were randomly assigned to receive either combination therapy or bevacizumab monotherapy. All patients received intravitreal bevacizumab at baseline, followed by dexamethasone implants or sham injections 1 week later. Monthly bevacizumab injections were given if the central subfield thickness (CST) was $>250 \mu \mathrm{m}$, and the combined group received a second implant at month 4 or 5 if CST was $>250 \mu \mathrm{m}$.

Results: At 6 months, several secondary endpoints were met. Patients receiving combined therapy required fewer bevacizumab reinjections compared to those receiving monotherapy (two versus three; $P=0.02$ ), experienced greater mean reductions in CST from randomization $(-56 \mu \mathrm{m}$ versus $+45 \mu \mathrm{m} ; P=0.01)$, and were more likely to have resolved all edema $(\mathrm{CST}<250 \mu \mathrm{m})(7 / 11$ versus $2 / 14 ; P=0.02)$. The primary endpoint was not met since mean visual acuity changes from baseline were similar in the two groups $(P=0.75)$.

Conclusion: In patients with macular edema due to vein occlusions, bevacizumab with dexamethasone implants produces greater improvements in macular thickness compared to bevacizumab monotherapy, despite fewer bevacizumab injections.

Keywords: dexamethasone implant, central retinal vein occlusion, branch retinal vein occlusion, vascular endothelial growth factor

\section{Introduction}

Branch (BRVO) and central (CRVO) retinal vein occlusions (RVOs) are the second most common retinal vascular disorders, occurring in $0.6 \%-1.1 \%$ and $0.1 \%-0.4 \%$ of patients in Australian and American populations, respectively. ${ }^{1,2}$ Decreased blood flow through the retinal vasculature results in tissue ischemia, upregulates vascular endothelial growth factor (VEGF), breaks down the blood-retinal barrier, and causes vision loss primarily because of macular edema. ${ }^{3,4}$ Grid-pattern laser photocoagulation improves edema and modestly increases vision in patients with BRVO, ${ }^{5}$ but is ineffective for patients with CRVO. ${ }^{6}$

Intraocular therapy with drugs that block the function of VEGF significantly resolves edema and improves vision compared to standard care. ${ }^{7-10}$ Impressive 
results from the pivotal Phase III registration trials led to the approval of ranibizumab ${ }^{7,8}$ and aflibercept $\mathrm{t}^{9,10}$ for the treatment of macular edema due to CRVO and ranibizumab for BRVO. ${ }^{11}$ Compared to ranibizumab and aflibercept, bevacizumab is generally more available, less expensive, and produces comparable gains in vision, but level I evidence for the treatment of RVOs is not available. ${ }^{12}$

Monthly intravitreal injections of anti-VEGF drugs dramatically improve vision, but when patients are treated pro re nata, macular edema increases and visual acuity (VA) decreases. ${ }^{8,13,14}$ Therefore, to maintain visual and anatomic gains achieved during the first 6 months of intensive therapy, patients may need to be examined and injected monthly, ${ }^{8,13,14}$ an intensive regimen that becomes unsustainable for many patients and physicians.

Macular edema due to vein occlusions is exquisitely sensitive to ranibizumab and aflibercept because of the highly elevated VEGF concentrations within the vitreous. ${ }^{15}$ However, VEGF is not the only upregulated inflammatory mediator in these eyes, as interleukin (IL)-1 $\beta$, IL-2, IL-5, IL-8, IL-9, IL-10, IL-12, IL-13, eotaxin, granulocyte colony stimulating factor, interferon-inducible $10 \mathrm{kDa}$ protein, monocyte chemotactic protein- 1 , and interferon- $\gamma$ are all overexpressed in eyes with CRVOs. ${ }^{16}$ The intraocular presence of several inflammatory mediators suggests that broad-based anti-inflammatory treatment with corticosteroids, as opposed to the focused VEGF binding action of ranibizumab and aflibercept, might be advantageous for some patients. ${ }^{16}$ The dexamethasone implant $0.7 \mathrm{mg}$ (DEX) is superior to laser photocoagulation and observation for the treatment of macular edema due to BRVO and CRVO.${ }^{17}$ Following intravitreal insertion of the implant, VA peaks at 3 months, but then decreases in tandem with falling intraocular drug concentrations. ${ }^{18}$ Combining the dexamethasone implant's extended duration of action with the dramatic improvements in VA achievable with anti-VEGF injections may lead to greater improvements in vision, with fewer injections and office visits and a lower total cost.

Herein we report the results of a 6-month pilot study that explored the effects of combined anti-VEGF (bevacizumab) and corticosteroid (dexamethasone implant) therapy on eyes with macular edema due to BRVO and CRVO, and compared them to bevacizumab monotherapy.

\section{Methods}

This prospective, institutional, single-masked, randomized trial was approved by the institutional review board Quorum International. Each subject provided written informed consent before enrollment.
From March 18, 2010, to March 15, 2011, 30 subjects were enrolled in the study. Eligible patients had macular edema of less than 1 year's duration due to BRVO or CRVO, with central subfield thickness $(\mathrm{CST})>250 \mu \mathrm{m}$ as measured by time-domain optical coherence tomography (Stratus $^{\circledR}$; Carl Zeiss Meditec, Inc, Dublin, CA, USA). Best corrected VA scores at baseline were $>24$ and $<80$ Early Treatment Diabetic Retinopathy Study (ETDRS) letters. Exclusion criteria included evidence of other retinal or retinal pigment epithelial abnormalities, a previous vitrectomy, preexisting glaucoma, and the injection of an intravitreal anti-VEGF drug in the study eye within the previous 6 weeks or a corticosteroid within the previous 8 weeks. The amount of retinal ischemia was not an exclusionary factor.

Subjects in this cohort were randomly assigned 1:1 to one of two study groups. The monotherapy group (15 eyes) received intravitreal bevacizumab (Avastin ${ }^{\circledR}$; Genentech, South San Francisco, CA, USA/Roche, Basel, Switzerland) $1.25 \mathrm{mg}$ at baseline followed by a sham dexamethasone implant (Ozurdex ${ }^{\circledR}$; Allergan, Irvine, CA, USA) injection at the time of randomization 1 week later. Additional bevacizumab injections were given at monthly intervals when the CST measured $>250 \mu \mathrm{m}$.

The combination therapy group (15 eyes) received intravitreal bevacizumab $1.25 \mathrm{mg}$ at baseline followed by an intravitreal DEX injection at the time of randomization 1 week later. Bevacizumab injections were repeated monthly when the CST measured $>250 \mu \mathrm{m}$. Reinjections of DEX or sham DEX (in the monotherapy group) were performed at month 4 or month 5 ( 1 week after the repeat bevacizumab injection) if the CST measured $>250 \mu \mathrm{m}$.

At each visit, best corrected ETDRS VAs were measured, and slit lamp examinations, intraocular pressure measurements, fundus examinations, and time-domain optical coherence tomography were performed. Fluorescein angiography was performed at baseline and at month 6 .

\section{Study endpoints}

The primary endpoint was improvement in VA in the combination group compared to the bevacizumab group at 6 months. Secondary endpoints included the mean changes in CST, the proportions of eyes with CST $<250 \mu \mathrm{m}$, and the number of bevacizumab injections required by each group.

\section{Statistical analysis}

Important baseline features of the cohort were characterized by descriptive statistics. Analysis of covariance (ANCOVA) models were constructed for important study endpoints (VA and CST) at 6 months, adjusting for randomization values. 
To compare the number of bevacizumab injections, an ANCOVA model examined the treatment effect, with CST (at randomization) as a covariate adjustment. Survival analyses were conducted on time to first bevacizumab retreatment and time to 15 -letter improvement in VA. Kaplan-Meier survival curves were used to compare the two conditions.

\section{Results \\ Baseline characteristics}

Fifteen eyes had CRVOs and 15 eyes had BRVOs. The numbers of patients with BRVO and CRVO did not differ significantly between the two treatment groups. The mean ( \pm standard deviation) VA scores in the monotherapy and combined groups at enrollment were $60 \pm 14$ and $57 \pm 13$ letters, which improved to $65 \pm 13$ and $66 \pm 9$ letters at randomization $(P=0.75)$; the mean CST measurements were $436 \mu \mathrm{m}$ and $412 \mu \mathrm{m}$ at enrollment, and $284 \mu \mathrm{m}$ and $282 \mu \mathrm{m}$ at randomization $(P=0.90)$.

Of the 15 eyes assigned to each treatment group, eleven of 15 in the combination therapy group and 14 of 15 in the monotherapy group completed the 6-month study. Among those examined at the 6-month visit, ten of eleven in the combined group and 13 of 14 in the monotherapy group completed all monthly visits, and one participant in each group missed one monthly visit. Of the patients lost to follow-up, patients in the combined group last completed visits at 1, 3, 4, and 4 months, and the monotherapy patient died due to a recurrence of esophageal carcinoma after completing the 4-month visit. Four patients in the combination therapy group withdrew from the study, one because of intolerable pain associated with the dexamethasone injection, two due to poor systemic health (one due to complications after cholecystectomy, one due to generalized malaise), and one could not be reached for follow-up examinations. Supplemental analysis indicates that the dropout group had similar baseline characteristics and responded similarly to patients who completed the trial.

Baseline characteristics of the two treatment groups are shown in Table 1.

\section{Treatments}

The median time to the first bevacizumab retreatment was longer in the combined group than in the monotherapy group ( 3 months versus 1 month; $P=0.003$ ) (Figure 1). Among subjects completing the study (Table 2), the median number of bevacizumab reinjections, adjusted for CST at randomization, was two in the combination therapy group and three in the monotherapy group $(P=0.02)$. The mean total number of injections (bevacizumab + DEX) was 2.9 in the combination therapy group and 2.7 in the monotherapy group. Three subjects in the combination therapy group and zero in the monotherapy group required no additional injections of bevacizumab after that performed at enrollment. A second DEX injection was given at month 4 or 5 in seven subjects in the combination therapy group.

\section{Effect of treatment on VA and CST}

VA improvements in the two groups followed similar patterns during the 6 months (Figure 2). Among subjects that completed the study, the mean change in VA from randomization to 6 months was $0.1 \pm 13.3$ letters in the combination therapy group compared with $2.3 \pm 7.7$ in the monotherapy group ( $P=0.75$, adjusted for VA at randomization) (Table 3). Only three eyes (two in the combination group [18\%], one in the monotherapy group [7\%]) improved by 15 letters.

Following the initial bevacizumab injections given to all subjects, the CST rapidly decreased by a mean of $-184 \pm 176 \mu \mathrm{m}$ by the time of randomization $(P<0.001)$ (Figure 3). From randomization through 6 months, the mean CST decreased by $-55.6 \pm 39.7 \mu \mathrm{m}$ in the combination therapy group and increased by $+45.4 \pm 100.1 \mu \mathrm{m}$ in the monotherapy group ( $P=0.01$, adjusted for CST at randomization) (Table 3 and Figure 3). Among subjects completing the 6-month visit, seven of eleven in the combination therapy group and two of 14 in the monotherapy group had CST $<250 \mu \mathrm{m}$ and changes from randomization of $\geq 25 \mu \mathrm{m}$ $(P=0.02)$. Improvements in VA and CST were similar among patients with BRVO and CRVO.

\section{Safety}

No serious safety concerns emerged in the study. One subject in the combination therapy group underwent cataract surgery and one in each treatment group experienced increased intraocular pressure $(>21 \mathrm{mmHg})$. Both of these subjects responded well to topical pressure-lowering medications and neither developed glaucomatous changes.

\section{Discussion}

The Standard Care vs Corticosteroid for Retinal Vein Occlusion (SCORE) ${ }^{19}$ and Global Evaluation of implantable dexamethasone in retinal vein occlusion with macular edema (GENEVA) $)^{17}$ trials demonstrated that intravitreal corticosteroids effectively resolve macular edema due to RVOs and improve VA by +11 to +12 letters compared to controls. Few studies have compared corticosteroids directly with 
Table I Enrollment and randomization characteristics of study participants

\begin{tabular}{|c|c|c|c|}
\hline Initial characteristics & $\begin{array}{l}\text { Bevacizumab plus } \\
\text { dexamethasone group } \\
\mathrm{N}=15\end{array}$ & $\begin{array}{l}\text { Bevacizumab } \\
\text { monotherapy group } \\
\mathrm{N}=15\end{array}$ & $P$-value \\
\hline Age in years, mean $\pm S D$ & $69 \pm 19$ & $67 \pm 13$ & 0.79 \\
\hline \multicolumn{4}{|l|}{ Race, $\mathrm{N}$} \\
\hline White & 15 & 14 & \multirow[t]{2}{*}{0.99} \\
\hline African-American & 0 & 1 & \\
\hline \multicolumn{4}{|l|}{ Sex, N } \\
\hline Male & 8 & 10 & \multirow[t]{2}{*}{0.71} \\
\hline Female & 7 & 5 & \\
\hline Type 2 diabetes, $\mathrm{N}$ & 4 & 2 & 0.65 \\
\hline \multicolumn{4}{|l|}{ Type of vein occlusion, $\mathrm{N}$} \\
\hline CRVO & 6 & 9 & \multirow[t]{2}{*}{0.47} \\
\hline BRVO & 9 & 6 & \\
\hline \multicolumn{4}{|l|}{ Lens status, $\mathrm{N}$} \\
\hline Phakic & 9 & 9 & \multirow[t]{2}{*}{0.99} \\
\hline PC IOL & 6 & 6 & \\
\hline Mean enrollment BCVA in letters, mean \pm SD & $57 \pm 13$ & $60 \pm 14$ & 0.67 \\
\hline \multicolumn{4}{|l|}{ Letter score (Snellen), number of eyes } \\
\hline $63-79(20 / 25-20 / 50)$ & 6 & 6 & \multirow[t]{3}{*}{0.87} \\
\hline $48-62(20 / 63-20 / 100)$ & 6 & 7 & \\
\hline $25-47(20 / / 25-20 / 320)$ & 3 & 2 & \\
\hline \multicolumn{4}{|l|}{ Enrollment OCT, median (25th, 75th percentile) } \\
\hline Central subfield thickness, $\mu \mathrm{m}$ & $412(354,606)$ & $436(373,579)$ & 0.68 \\
\hline Randomization OCT, median (25th, 75th percentile) & & & \multirow[t]{2}{*}{0.98} \\
\hline Central subfield thickness, $\mu \mathrm{m}$ & $282(26|, 3| 9)$ & $284(260,350)$ & \\
\hline \multicolumn{4}{|l|}{ Previous number of treatments, $\mathrm{N}$} \\
\hline Focal laser & & & \multirow[t]{4}{*}{0.34} \\
\hline 0 & 13 & 15 & \\
\hline 1 & 1 & 0 & \\
\hline 2 & 1 & 0 & \\
\hline \multicolumn{4}{|l|}{ Bevacizumab injections } \\
\hline 0 & 10 & 11 & \\
\hline 1 & 2 & 1 & \\
\hline 2 & 1 & 1 & \\
\hline 3 & 1 & 1 & \\
\hline 4 & I & 1 & \\
\hline Intravitreal triamcinolone injections & & & 0.99 \\
\hline 0 & 14 & 14 & \\
\hline 1 & 1 & 1 & \\
\hline Intravitreal dexamethasone injections & & & 0.99 \\
\hline 0 & 15 & 14 & \\
\hline 1 & 0 & 0 & \\
\hline 2 & 0 & 1 & \\
\hline Duration of RVO in years, mean $\pm S D$ & $0.4 \pm 0.4$ & $0.3 \pm 0.3$ & 0.57 \\
\hline
\end{tabular}

Abbreviations: BRVO, branch retinal vein occlusion; CRVO, central retinal vein occlusion; OCT, optical coherence tomography; RVO, retinal vein occlusion; SD, standard deviation; BCVA, best corrected visual acuity; PC IOL, posterior chamber intraocular lens; N, number.

anti-VEGF drugs, but in a 6-month prospective trial, comparable improvements in VA and macular edema were achieved with either DEX or bevacizumab, despite significantly fewer DEX injections. ${ }^{20}$ The long intravitreal half-life of triamcinolone (18 days) $)^{21}$ and the prolonged structural integrity of the biodegradable dexamethasone implant ${ }^{18}$ result in therapeutic responses that last 3-6 months after single injections. This sustained duration of action may be a therapeutic advantage since the Central Retinal Vein Occlusion Study: Evaluation of Efficacy and Safety (CRUISE)/HORIZON study; ${ }^{8}$ VEGF Trap-Eye Investigation of Efficacy and Safety in Central Retinal Vein Occlusion study (COPERNICUS); ${ }^{13}$ and GALILEO $^{14}$ trials showed that, despite 6 months of regular anti-VEGF injections, decreasing surveillance frequency coupled with pro re nata drug administration resulted in increasing edema and decreasing vision. 


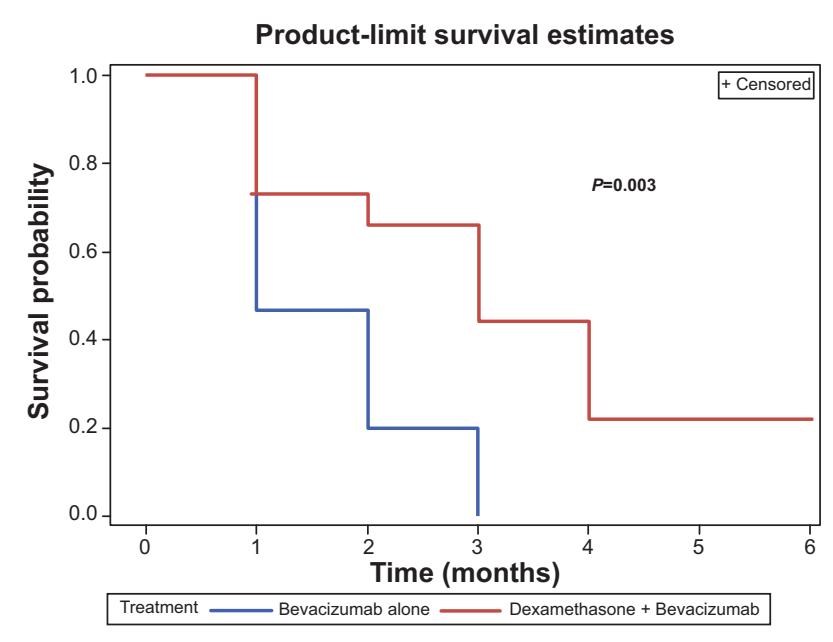

Figure I Survival probability graph showing the lengths of time in which eyes in the bevacizumab monotherapy and combined groups remained without requiring retreatments.

Corticosteroids have significant anti-inflammatory actions that may incrementally benefit anti-VEGF blockade for the treatment of edema due to RVOs. The combined therapy group experienced less variability in macular thickness throughout the study and significantly less edema at the 6-month endpoint, which we believe was due to both the extended duration of action of the DEX implant and the potency of combination therapy. Long-term visual function in eyes with RVOs partly depends upon the duration and severity of retinal ischemia, factors over which we have no control. Correlation between macular thinning and VA improvements in exudative maculopathies is frequently low, ${ }^{22}$ and the findings from this trial are no exception. The long-term consequences of thicker maculas are unclear, but increasing edema after 6 months in the CRUISE/HORIZON,${ }^{8}$ COPERNICUS, ${ }^{13}$ and GALILEO $^{14}$ trials resulted in decreasing VA. We believe that less macular edema leads to better long-term vision, and future combination therapy trials should extend to 2 years to better explore this relationship.
In a related prospective RVO study without a control group, patients receiving dexamethasone implants 2 weeks after bevacizumab injections improved by an additional +5.7 letters at 6 months. ${ }^{23}$ The mean time to first retreatment was 129 days, and $18 \%$ of eyes required no further injections. This additional improvement in VA suggests that the baseline characteristics of patients from this trial and ours differed. Injecting dexamethasone implants into eyes with recalcitrant macular edema, despite frequent anti-VEGF injections, may be beneficial. In a small retrospective series with 34 eyes, average VA and macular thickness improved after DEX injections by $0.26 \operatorname{logMAR}$ and $-146.8 \mu \mathrm{m}$ after failing to improve with two previous bevacizumab injections. ${ }^{24}$

The less favorable safety profiles associated with intraocular corticosteroid therapy have tempered the successes reported in the $\mathrm{SCORE}^{19}$ and GENEVA ${ }^{17}$ trials. Intravitreal injections of triamcinolone are associated with a dose-dependent (20\% with $1 \mathrm{mg}$ dose; $40 \%$ with $4 \mathrm{mg}$ dose) incidence of elevated intraocular pressure. In the Fluocinolone Acetonide in Human Aqueous (FAMOUS) Study, aqueous concentrations of fluocinolone acetonide were five times higher in patients receiving the high-dose implant ( $6 \mu \mathrm{g} /$ day) compared to those receiving the lowerdose implant ( $2 \mu \mathrm{g} /$ day $)$, and the rates of glaucoma filtration surgery at 1 year were nine times higher. ${ }^{25}$ The dexamethasone implant provides therapeutic drug concentrations with a low sustained release rate resulting in $12.6 \%$ and $15.4 \%$ incidences of intraocular pressure elevation after the first and second treatments. ${ }^{17}$ Singer et al reported an $18 \%$ incidence of elevated intraocular pressure, with one patient (3\%) requiring a selective laser trabeculoplasty. ${ }^{23}$ In our study, only one patient in each treatment group (combination therapy: 9\%; monotherapy: $7 \%$ ) required pressure-lowering medications and neither developed glaucomatous damage. This compares relatively favorably with the reported incidences of pressure elevation due to ranibizumab (3\%) and bevacizumab (10\%). ${ }^{26}$

Table 2 Number of bevacizumab reinjections in subjects who completed the study

\begin{tabular}{|c|c|c|}
\hline \multirow{2}{*}{$\begin{array}{l}\text { Number of additional } \\
\text { bevacizumab injections }\end{array}$} & \multicolumn{2}{|l|}{ Treatment group } \\
\hline & $\begin{array}{l}\text { Bevacizumab plus dexamethasone } \\
\text { group, number of eyes (\%) }\end{array}$ & $\begin{array}{l}\text { Bevacizumab monotherapy group, } \\
\text { number of eyes (\%) }\end{array}$ \\
\hline 0 & $3(27)$ & $0(0)$ \\
\hline I & $2(18)$ & $3(2 I)$ \\
\hline 2 & $2(18)$ & $3(2 I)$ \\
\hline 3 & $2(18)$ & $3(2 I)$ \\
\hline 4 & $0(0)$ & $2(14)$ \\
\hline 5 & $2(18)$ & $3(2 I)$ \\
\hline Total & II (I00) & $14(100)$ \\
\hline
\end{tabular}


Among month 6 completers - BCVA means

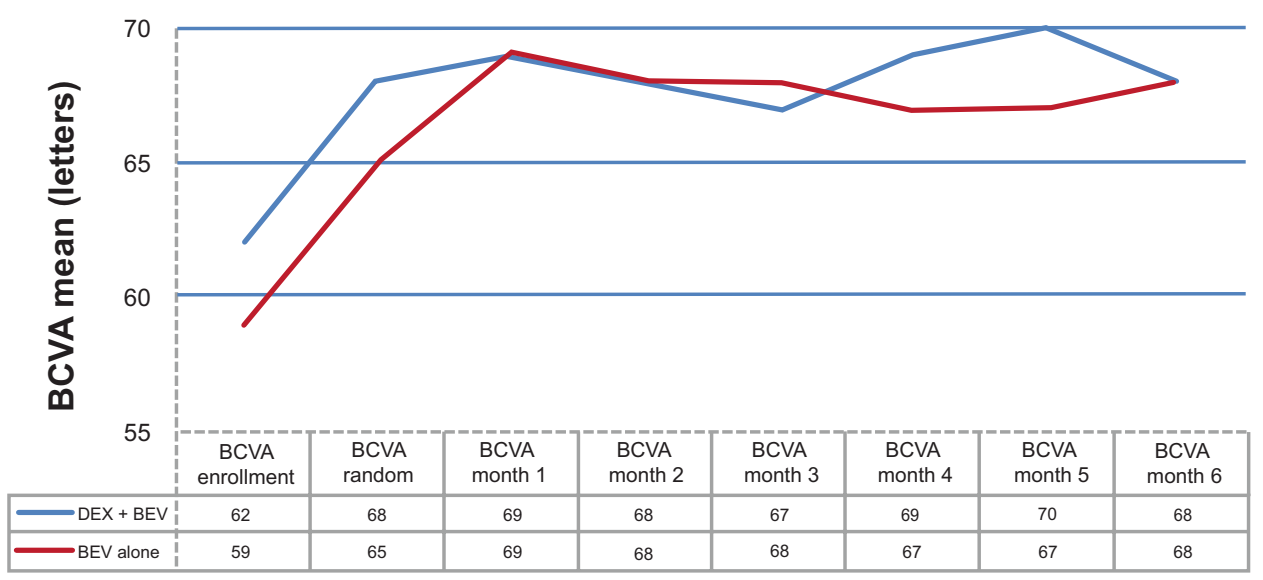

Figure 2 Mean BCVAs in the BEV monotherapy and BEV/DEX combined groups from enrollment through 6 months. Abbreviations: BCVA, best corrected visual acuity; BEV, bevacizumab; DEX, dexamethasone implant $0.7 \mathrm{mg}$.

After 1 year of dexamethasone treatment in the GENEVA trial, cataracts progressed in $29.8 \%$ of patients, but only $1.3 \%$ underwent cataract surgery. ${ }^{17}$ Only one $(6.7 \%)$ of our patients receiving DEX underwent cataract surgery, but the glaucoma and cataract incidences in our trial may appear low because our follow-up was only 6 months.

Five of the 30 enrolled eyes did not complete the full study, but four completed at least 3 months of follow-up. Baseline and follow-up data from these patients suggests that incomplete follow-up was not the source of any meaningful bias. Injection of the larger bore (22-gauge) dexamethasone implant is more uncomfortable than antiVEGF injections, but highly motivated patients tolerate DEX injections quite well for 1 year, as evidenced by the $95 \%$ retention rate in the large GENEVA trial. ${ }^{17}$ Furthermore, the manufacturer has recently redesigned the needle tip, making implantation easier and less painful. Since the high dropout rate in our study was mostly due to patients with advanced systemic illnesses (three of five patients), future trials should tighten the exclusion criteria to prevent the enrollment of patients who would be unlikely to complete the trial.

Table 3 Visual acuity and OCT outcomes among 6-month completers

\begin{tabular}{|c|c|c|}
\hline Patient characteristic & $\begin{array}{l}\text { Bevacizumab plus } \\
\text { dexamethasone } \\
\text { group } \mathbf{N}=\text { I I }\end{array}$ & $\begin{array}{l}\text { Bevacizumab } \\
\text { monotherapy } \\
\text { group } N=14\end{array}$ \\
\hline \multicolumn{3}{|l|}{ Best corrected visual acuity in letters, mean $\pm S D$} \\
\hline At enrollment & $62 \pm 10$ & $59 \pm 14$ \\
\hline At randomization & $68 \pm 9$ & $65 \pm 13$ \\
\hline At 6 months & $68 \pm 12$ & $68 \pm 13$ \\
\hline$\Delta$ (randomization to 6 months) & $+0.1 \pm 13.3$ & $+2.3 \pm 7.7$ \\
\hline \multicolumn{3}{|l|}{ Distribution of change, $\mathrm{N}$} \\
\hline$\geq$ I5-letter improvement & 2 & I \\
\hline 10- to 14-letter improvement & I & 2 \\
\hline 5- to 9-letter improvement & I & 1 \\
\hline Unchanged \pm 4 letters & 4 & 8 \\
\hline 5-9 letters worse & 2 & 2 \\
\hline I0-14 letters worse & 0 & 0 \\
\hline$\geq 15$ letters worse & I & 0 \\
\hline \multicolumn{3}{|l|}{ OCT central subfield thickness $(\mu \mathrm{m})$, mean $\pm \mathrm{SD}$} \\
\hline At enrollment & $427 \pm 103$ & $5|3 \pm 23|$ \\
\hline At randomization & $320 \pm 72$ & $287 \pm 49$ \\
\hline At 6 months & $264 \pm 77$ & $333 \pm 95$ \\
\hline \multicolumn{3}{|l|}{$\Delta$ (randomization to 6 months) } \\
\hline At 6 months, number of eyes $<250 \mu \mathrm{m}$ with $\Delta>25 \mu \mathrm{m}$ & $-56 \pm 40$ & $+45 \pm 100$ \\
\hline from randomization & 7 & 2 \\
\hline
\end{tabular}

Abbrevations: OCT, optical coherence tomography; SD, standard deviation; N, number. 


\section{Among month 6 completers - OCT CST mean $(\mu \mathrm{m})$}

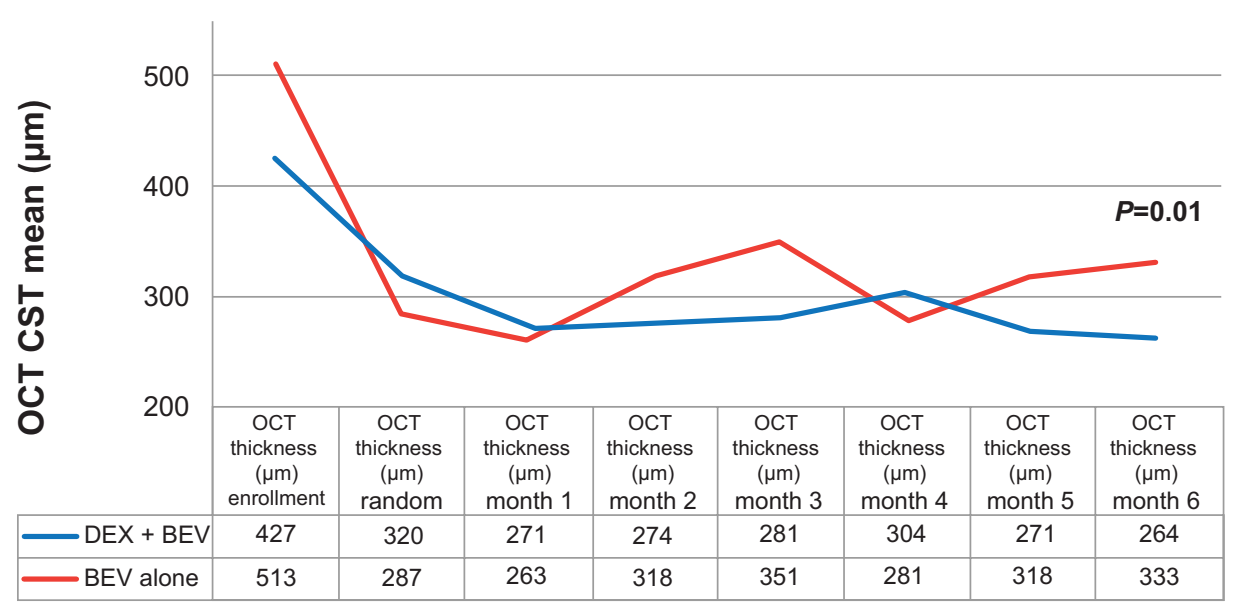

Figure 3 Mean spectral-domain OCT-measured CSTs within the BEV monotherapy and BEV/DEX combined groups from enrollment through 6 months. Abbreviations: BEV, bevacizumab; CST, central subfield thickness; DEX, dexamethasone implant $0.7 \mathrm{mg}$; OCT, optical coherence tomography.

Our study demonstrates that combining bevacizumab with the dexamethasone implant decreases the median number of required anti-VEGF injections over a 6 month period. The total numbers of injections (bevacizumab + dexamethasone [mean: 2.9] versus bevacizumab [mean: 2.7]) are similar between the two treatment arms, but we believe that longer-duration studies would better define the total injection load (bevacizumab + dexamethasone) needed to produce an optimal treatment response. Unfortunately, this study failed to meet its primary endpoint since combination therapy failed to improve VA more than anti-VEGF monotherapy. Our findings do not support the notion that combination therapy produces superior gains in vision over monotherapy.

Like all pilot studies, ours has several weaknesses. Enrollment in the trial was small, and retention in the combination therapy group was disappointingly low. The 6-month primary endpoint, similar to that used in the pivotal RVO trials, ${ }^{7-11}$ may have been too short a time for best assessing the efficacy and safety of combination therapy. There were nonsignificant differences in the numbers of BRVO and CRVO patients in the two treatment groups. Though the monotherapy group, which had more CRVO patients, had lower average VA and higher average CST at enrollment, the VA and CST in the two treatment groups were nearly identical at the time of randomization. Furthermore, Phase III registration trials ${ }^{7,9-11}$ with ranibizumab and aflibercept show that 6-month VA improvements are nearly identical in BRVO and CRVO patients. Though level I evidence supports the use of both ranibizumab and aflibercept for RVOs, robust data supporting the use of bevacizumab is not yet available. ${ }^{27-29}$ Future RVO trials need to perform head-to-head comparisons between bevacizumab, ranibizumab, and aflibercept.

\section{Conclusion}

This pilot trial suggests that, compared to bevacizumab monotherapy, combining bevacizumab with the dexamethasone implant leads to more rapid improvements in vision and CST in patients with macular edema due to RVOs, while requiring fewer bevacizumab injections. For patients who are already pseudophakic and who are not steroid responders, adding DEX to a regimen of bevacizumab injections is unlikely to significantly increase the risk of complications, and for those patients who are unable to visit physicians' offices monthly, less frequent treatments with combination therapy may be a palatable alternative to the more frequently administered bevacizumab monotherapy. We look forward to future trials that will better define the role of this approach in clinical practice.

\section{Acknowledgments}

An independent investigator-initiated grant was provided by Allergan, Inc. to defray the costs of this study. This study was supported by Allergan via an independent and unrestricted research grant. Allergan had the opportunity to review the final version of the manuscript to: (a) address any factual inaccuracies with the publisher as it relates to any Allergan materials or (b) request the redaction of information that Allergan deems confidential or proprietary. However, Allergan has made no recommendations.

\section{Disclosure}

RK Maturi: Raj K Maturi has served on advisory boards for Allergan and Regeneron, as a consultant for Ely Lilly and the Jaeb Center for Health Research, as a sub-investigator for Alcon, Alimera and Quark, and as a principal investigator for Allergan, Sanofi, Eyegate, GlaxoSmithKline, the Jaeb Center, Parexel, and Santen. Michael W Stewart has served 
on advisory boards for Allergan and Regeneron, and as a consultant for Boehringer-Ingelheim. The authors report no other conflicts of interest in this work.

\section{References}

1. Mitchell P, Smith W, Chang A. Prevalence and associations of retinal vein occlusion in Australia: the Blue Mountains Eye Study. Arch Ophthalmol. 1996;114:1243-1247.

2. Klein R, Klein BE, Moss SE, Meuer SM. The epidemiology of retinal vein occlusion: the Beaver Dam Eye Study. Trans Am Ophthalmol Soc. 2000;98:133-143.

3. Antonetti DA, Barber AJ, Khin S, Lieth E, Tarbell JM, Gardner TW. Vascular permeability in experimental diabetes is associated with reduced endothelial occludin content: vascular endothelial growth factor decreases occludin in retinal endothelial cells. Penn State Retina Research Group. Diabetes. 1998;4:1953-1959.

4. Rehak J, Rehak M. Branch retinal vein occlusion: pathogenesis, visual prognosis, and treatment modalities. Curr Eye Res. 2008;33:111-131.

5. [No authors listed]. Argon laser photocoagulation for macular edema in branch vein occlusion. The Branch Vein Occlusion Study Group. Am J Ophthalmol. 1984;98:271-282.

6. [No authors listed]. Evaluation of grid pattern photocoagulation for macular edema in central vein occlusion. The Central Vein Occlusion Study Group M report. Ophthalmology. 1995;102:1425-1433.

7. Campochiaro PA, Brown DM, Awh CC, et al. Sustained benefits from ranibizumab for macular edema following central retinal vein occlusion: twelve-month outcomes of a phase III study. Ophthalmology. 2011;118:2041-2049.

8. Heier JS, Campochiaro PA, Yau L, et al. Ranibizumab for macular edema due to retinal vein occlusions: long-term follow-up in the HORIZON trial. Ophthalmology. 2012;119:802-809.

9. Brown DM, Heier JS, Clark WL, et al. Intravitreal aflibercept injection for macular edema secondary to central retinal vein occlusion: 1-year results from the phase 3 COPERNICUS study. Am J Ophthalmol. 2013;155(3):429-437.e7.

10. Holz FG, Roider J, Ogura Y, et al. VEGF Trap-Eye for macular oedema secondary to central retinal vein occlusion: 6-month results of the phase III GALILEO study. Br J Ophthalmol. 2013;97:278-284.

11. Campochiaro PA, Heier JS, Feiner L, et al; BRAVO Investigators. Ranibizumab for macular edema following branch retinal vein occlusion: six-month primary end point results of a phase III study. Ophthalmology. 2010;117:1102-1112.e1.

12. Pielen A, Feltgen N, Isserstedt C, Callizo J, Junker B, Schmucker C. Efficacy and safety of intravitreal therapy in macular edema due to branch and central retinal vein occlusion: a systematic review. PLos One. 2013;8(10):e78538.

13. Clark WL. Two-year results of the COPERNICUS study evaluating intravitreal aflibercept injection (IAI) for macular edema secondary to central retinal vein occlusion (CRVO). Association for Research in Vision and Ophthalmology; May, 2013; Seattle, WA.

14. Ogural Y, Korobelnik JF, Roider J, et al. Eighteen-month results of the GALILEO study evaluating intravitreal aflibercept injection (IAI) for macular edema secondary to central retinal vein occlusion (CRVO). Association for Research in Vision and Ophthalmology; May, 2013; Seattle, WA.

Clinical Ophthalmology

\section{Publish your work in this journal}

Clinical Ophthalmology is an international, peer-reviewed journal covering all subspecialties within ophthalmology. Key topics include: Optometry; Visual science; Pharmacology and drug therapy in eye diseases; Basic Sciences; Primary and Secondary eye care; Patient Safety and Quality of Care Improvements. This journal is indexed on Submit your manuscript here: http://www.dovepress.com/clinical-ophthalmology-journal
15. Aiello LP, Avery RI, Arrigg PG, et al. Vascular endothelial growth factor in ocular fluid of patients with diabetic retinopathy and other retinal disorders. $N$ Engl J Med. 1994;331:1480-1487.

16. Suzuki Y, Nakazawa M, Suzuki K, Yamazaki H, Miyagawa Y. Expression profiles of cytokines and chemokines in vitreous fluid in diabetic retinopathy and central retinal vein occlusion. Jpn J Ophthalmol. 2011;55: 256-263.

17. Haller JA, Bandello F, Belfort R Jr, et al; Ozurdex GENEVA Study Group, Li J. Dexamethasone intravitreal implant in patients with macular edema related to branch or central retinal vein occlusion twelve-month study results. Ophthalmology. 2011;118:2453-2460.

18. Chang-Lin JE, Attar M, Acheampong AA, et al. Pharmacokinetics and pharmacodynamics of a sustained-release dexamethasone intravitreal implant. Invest Ophthalmol Vis Sci. 2011;52:80-86.

19. Scott IU, Ip MS, VanVeldhuisen PC, et al; SCORE Study Research Group. A randomized trial comparing the efficacy and safety of intravitreal triamcinolone with standard care to treat vision loss associated with macular edema secondary to branch retinal vein occlusion: the Standard Care vs Corticosteroid for Retinal Vein Occlusion (SCORE) study report 6. Arch Ophthalmol. 2009;127:1115-1128.

20. Guignier B, Subilia-Guignier A, Fournier I, Ballonzoli L, Speeg-Schatz C, Gaucher D. Prospective pilot study: efficacy of intravitreal dexamethasone and bevacizumab injections in the treatment of macular oedema associated with branch retinal vein occlusion. Ophthalmologica. 2013;230(1):43-49.

21. Tano Y, Sugita G, Abrams G, Machemer R. Inhibition of intraocular proliferations with intravitreal corticosteroids. Am J Ophthalmol. 1980;89:131-136.

22. Flaxel CJ, Edwards AR, Aiello LP, et al. Factors associated with visual acuity outcomes after vitrectomy for diabetic macular edema: diabetic retinopathy clinical research network. Retina. 2010; 30(9):1488-1495.

23. Singer MA, Bell DJ, Woods P, et al. Effect of combination therapy with bevacizumab and dexamethasone intravitreal implant in patients with retinal vein occlusion. Retina. 2012;32:1289-1294.

24. Sharareh B, Gallemore R, Taban M, Onishi S, Wallsh J. Recalcitrant macular edema after intravitreal bevacizumab is responsive to an intravitreal dexamethasone implant in retinal vein occlusion. Retina. 2013;33:1227-1231.

25. Campochiaro PA, Nguyen QD, Hafiz G, et al. Aqueous levels of fluocinolone acetonide after administration of fluocinolone acetonide inserts or fluocinolone acetonide implants. Ophthalmology. 2013;120:583-587.

26. Good TJ, Kimura AE, Mandava N, Kahook MY. Sustained elevation of intraocular pressure after intravitreal injections of anti-VEGF agents. Br J Ophthalmol. 2011;95:1111-1114.

27. Stahl A, Agostini H, Hansen LL, Feltgen N. Bevacizumab in retinal vein occlusion-results of a prospective case series. Graefes Arch Clin Exp Ophthalmol. 2007;245:1429-1436.

28. Prager F, Michaels S, Kriechbaum K, et al. Intravitreal bevacizumab (Avastin) for macular oedema secondary to retinal vein occlusion: 12-month results of a prospective clinical trial. $\mathrm{Br} J$ Ophthalmol. 2009;93:452-456.

29. Rabena MD, Pieramici DJ, Castellarin AA, Nasir MA, Avery RL. Intravitreal bevacizumab (Avastin) in the treatment of macular edema secondary to branch retinal vein occlusion. Retina. 2007;27:419-425.

\section{Dovepress}

PubMed Central and CAS, and is the official journal of The Society of Clinical Ophthalmology (SCO). The manuscript management system is completely online and includes a very quick and fair peer-review system, which is all easy to use. Visit http://www.dovepress.com/ testimonials.php to read real quotes from published authors. 